\title{
"Alexa, Can You Be My Family Medicine Doctor?" The Future of Family Medicine in the Coming Techno-World
}

\author{
Allen F. Shaughnessy, PharmD, MMedEd, David C. Slawson, MD, and \\ Ashley P. Duggan, PhD
}

Even before social distancing disrupted normative expectations and prompted an immediate shift to remote doctor/patient interactions, technology companies-Amazon, Apple, and Google-were preparing to disrupt medical care through the innovative use of technology. This article presents a possible scenario for how technology, in the near future, will completely up-end primary care practice. What does face-to-face interaction accomplish that cannot be done remotely? What do family physicians offer that cannot be accomplished by technology? More than just relationship, family medicine brings the therapeutic use of the self to engage with people, an ability to advocate for patients, and the ability to step back and reflect on the power of relationships. In addition, family physicians bring wisdom, making decisions in the liminal state between patient and physician, the resulting product of the human connection but also the ability to manage complexity using the best evidence. The ability to do both gives family medicine physician the skills to leverage but also control the coming big data. (J Am Board Fam Med 2021;34:430-434.)

Keywords: Clinical Decision-Making, Communication, Evidence-Based Practice, Family Medicine, Family Physicians, Narrative Medicine, Organizational Innovation, Physician's Practice Patterns, Primary Health Care, Technology

That it will ever come into general use, notwithstanding its value, is extremely doubtful; because its beneficial application requires much time and gives a good bit of trouble both to the patient and the practitioner; because its bue and character are foreign and opposed to all our habits and associations.

-From the translator's preface to Laennec's (1835) book on the use of his new invention, the stethoscope ${ }^{1}$

The smartphone was introduced less than 15 years ago. Few of us can imagine getting through

Submitted 5 May 2020; revised 15 July 2020; accepted 16 July 2020.

From the Department of Family Medicine, Tufts University School of Medicine, Boston, MA (AFS); and Cambridge Health Alliance, Cambridge, MA (AFS); Atrium Health, Charlotte, NC (DCS); University of North Carolina Chapel Hill (DCS); Communication Department, Boston College, Department of Family Medicine, Tufts University School of Medicine (APD).

Funding: None.

Conflict of interest: None declared.

Corresponding author: Allen F. Shaughnessy, PharmD, MMedEd, Department of Family Medicine, Tufts University School of Medicine, 145 Harrison Ave, Boston, MA 02111 (E-mail: Allen.Shaughnessy@tufts.edu). the day without ours. Similarly, the stethoscope quickly went from oddity to essential data information tool. The introduction of new technology creates its own necessity.

Tech giants are about to upend primary care practice. ${ }^{2,3}$ Do not shoot the messenger-regardless of what we want, changes are going to happen. What will be the impact on family medicine? Will there still be a need for family physicians to do whatever it is that only family physicians do? What is it that family physicians are best at doing? What would be lost if technology is substituted for faceto-face communication in primary care?

Considering technology first prompts some reflection about the role of family medicine physicians. According to a Greek parable, the fox is good at many things. Clever and resourceful on the hunt, it can develop cunning and complex strategies to "outfox" its prey. On the other hand, the hedgehog knows one big thing. When attacked, it rolls up into a little ball of outward-pointing spikes. Does not matter the threat—roll up and wait it out. ${ }^{4}$

Are family physicians foxes, thoughtfully adapting to their patients' needs, the needs of the 
community, and the ever-changing landscape that is medical practice? Or, are family physicians hedgehogs, doing one big thing that cannot be replaced by other clinicians or new technologies? What will be the role of emerging technologies in considering this question-will technology augment or replace the particular "charism" or way of being of family physicians?

\section{The (Near) Future}

Consider this office visit coming soon: the patient you are about to see, new to you, is a 54-year-old woman. Diabetes, her stated chief concern, could have been managed at home via Amazon Care, ${ }^{5}$ though she has requested this face-to-face visit. With her permission, your electronic health record system already has collected data from her home-based technology (Amazon Alexa, Fitbit, her bed, pillow, thermostat, water heater, iPhone), her Internet browser history, social media use data (Facebook), and supermarket loyalty cards ${ }^{6}$ analyzed it through an artificial intelligence processor, and integrated it with her existing office-based medical information. Her use of her smartphone-the manner in which she taps, scrolls, and clicks-has been analyzed to determine her "digital phenotype," depression. One of the patient guides, a member of your care team, has already spent 15 minutes with her, collecting information, answering her questions, and reviewing this information, which is presented on an interactive wall screen using state-of-the-art pictograms. Embedded technology in the examination room has been reading her facial expressions and body language (Apple is partnering with Duke University to develop a facial recognition program to analyze a child's emotion and behavior to detect autism?), has analyzed her voice for stress level (a company is marketing a product that can detect "vocal biomarkers" that can detect sadness, loneliness, cardiovascular disease ${ }^{10}$ ), and has performed a semantic analysis of the conversation with the patient guide (though not yet used in medical care, real-time semantic analysis and voice stress analysis are used to monitor customer service calls to determine customer satisfaction ${ }^{11}$ ).

All this information has been analyzed through an artificial intelligence medical software. While the patient's visit is for diabetes, based on browser history and use of a phone-based application, the tool identifies the likely unstated concern about a mole on the patient's upper leg and, based on credit card data combined with activity monitoring, that the patient has not smoked for 2 months. On your tablet, you receive the information in the table as a series of infographics (Figure 1).

Based on the gathered information, the tool suggests the following plan for conducting the visit, in order of priority (allotted time, 7 minutes) (Figure 2).

\section{Dr. Google Will See You Now}

This seemingly wild imagining of the future is not that far off. There are more than 100,000 health apps available for Google Android and Apple iOS platforms. While not all patients will use the technologies suggested in this scenario, the 3 major technology companies-Amazon, Apple, and Google-have systems already available for collecting data and synthesizing it in a way that make current electronic health records look anemic. It does not take much: way back in 1997, a researcher demonstrated that she could link a publicly available population registry (eg, a voter list) to identify the medical record of the governor of Massachusetts, even though the medical record had been stripped of all identifying information. ${ }^{12}$

Google Health aims to use its know-how "to assist in diagnosing cancer, predicting patient outcomes, preventing blindness, and much more." ${ }^{\text {13 }}$ Apple is touting the use of its technology to make care "more efficient, more personalized, and ultimately more buman" (emphasis added). ${ }^{14}$

How can we prepare family physicians for new roles in which technology can process more information faster and better than humans, when time and continuity are limited in a system aimed at lowering costs? How can we continue to help patients who on the one hand have lowered expectations ${ }^{15}$ and on the other hand have a need, more than ever, for someone to hear their story ${ }^{16}$ and fix it? ${ }^{17}$ In this potential future techno-empowered "care" system, what happens to the tradition in family medicine of recruiting, retaining, training, and sustaining a subset of physicians who find satisfaction in the unique longitudinal relationships with patients and families?

The news is not all bad; most of it is good, and, as demonstrated by the ubiquity of the stethoscope and smartphone, likely to be adopted. The diagnostic process currently consists of sifting patient data, both overt and intuited, and gradually moving to a label that prioritizes some data and ignores other. 
Figure 1. Example of Patient Data That Can Be Collected through Existing Electronic Tools and Analyzed via Artificial Analysis.

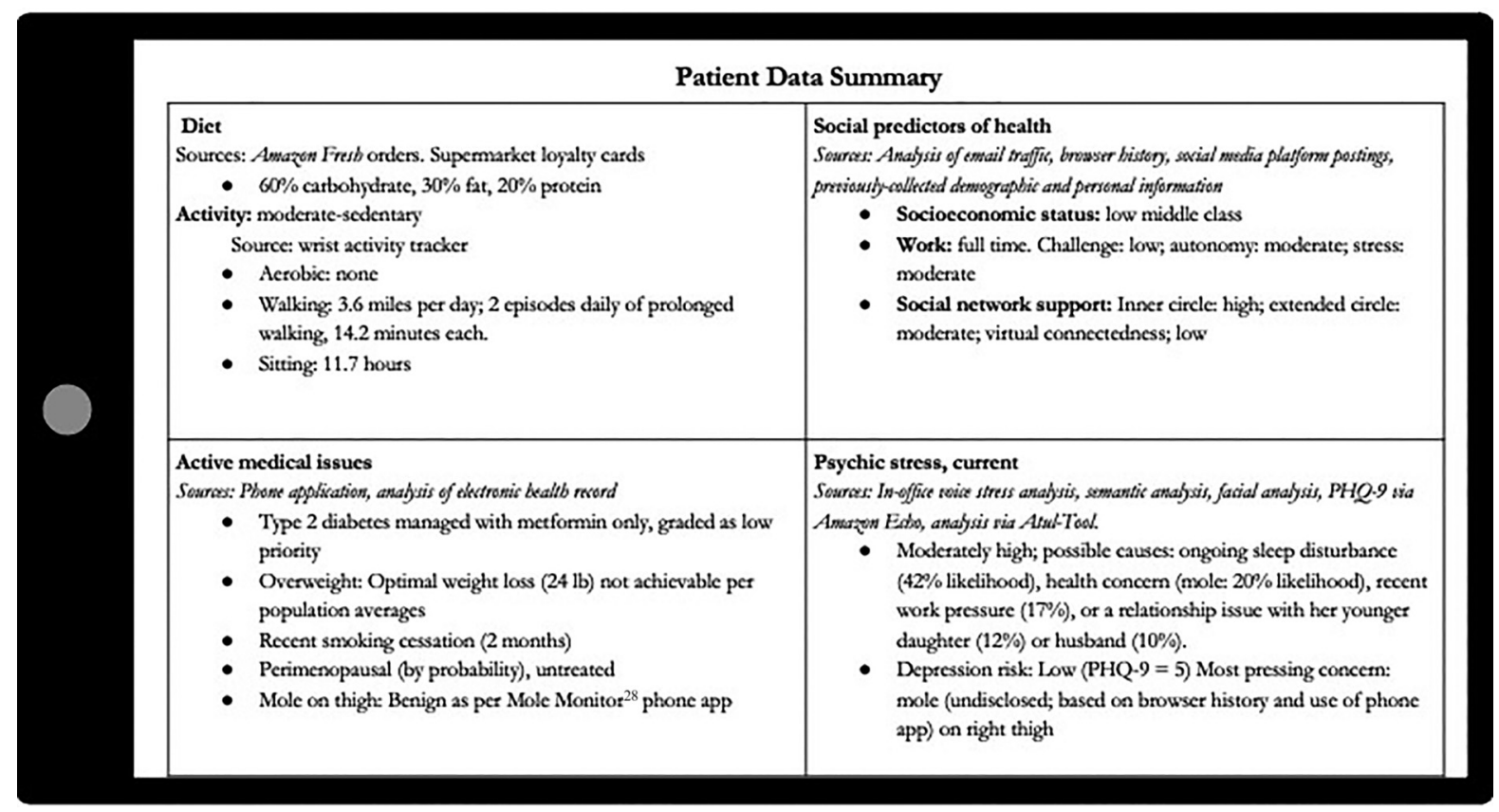

But what if we had the technology to attend to ALL of the detail, along with integrating data that would never be collectable during the office visit? Take, for example, the mole mentioned in the example. The patient might not mention it at all or mention it as an, "oh, by the way" agenda item toward the conclusion of the visit, necessitating either a return visit or an examination in the moment, either of which may focus more on the diagnosis rather than the impact of the presence of the mole on the patient's psychic stress.

\section{Generalism as Specialty: Are Family Physicians Foxes or Hedgehogs?}

Family-physicians-as-foxes is an obvious answer, given the breadth of the specialty. Family physicians treat ailments and provide comprehensive care to patients of all ages, providing acute, chronic, and preventive medical care services. They can be found in rural, suburban, or urban areas, providing care to both the underserved and overserved of all socioeconomic strata. They practice in settings ranging from direct primary care to accountable care organizations. However, this wide range is likely to be segmented as other clinicians and models, such as pharmacy-based and urgent care clinics, telemedicine, and team-based care, appeal to certain groups.

But maybe the family-physician-as-hedgehog is a better model. Maybe scope of practice shouldn't be the defining characteristic of family medicine practice. After all, isn't the longitudinal relationship the cornerstone of family medicine? What family medicine doctors and primary care doctors bring, in addition to biomedical knowledge, is the human understanding of people trying to get through the current challenges, the ability to humanize and personalize the care of each patient based on needs and values, the ability to advocate for patients and to connect them with resources, and the ability to step back and reflect on the power of relationships. This therapeutic use of the self is the communicative interconnection between core values of family medicine and the human ability to engage with the patient in a humanistic way. It is an amalgamation of the illness in the context of patients' identify and their relationships, ${ }^{18}$ situated within the unique relationship between doctor and patient, with the answer emerging during the human-to-human connection. ${ }^{4}$

The move toward retail medicine and diminishing expectations of people seeking health care may move relationship building away from 
Figure 2. Example of a Care Plan Generated by Artificial Intelligence Analysis of Electronically Collected Information.

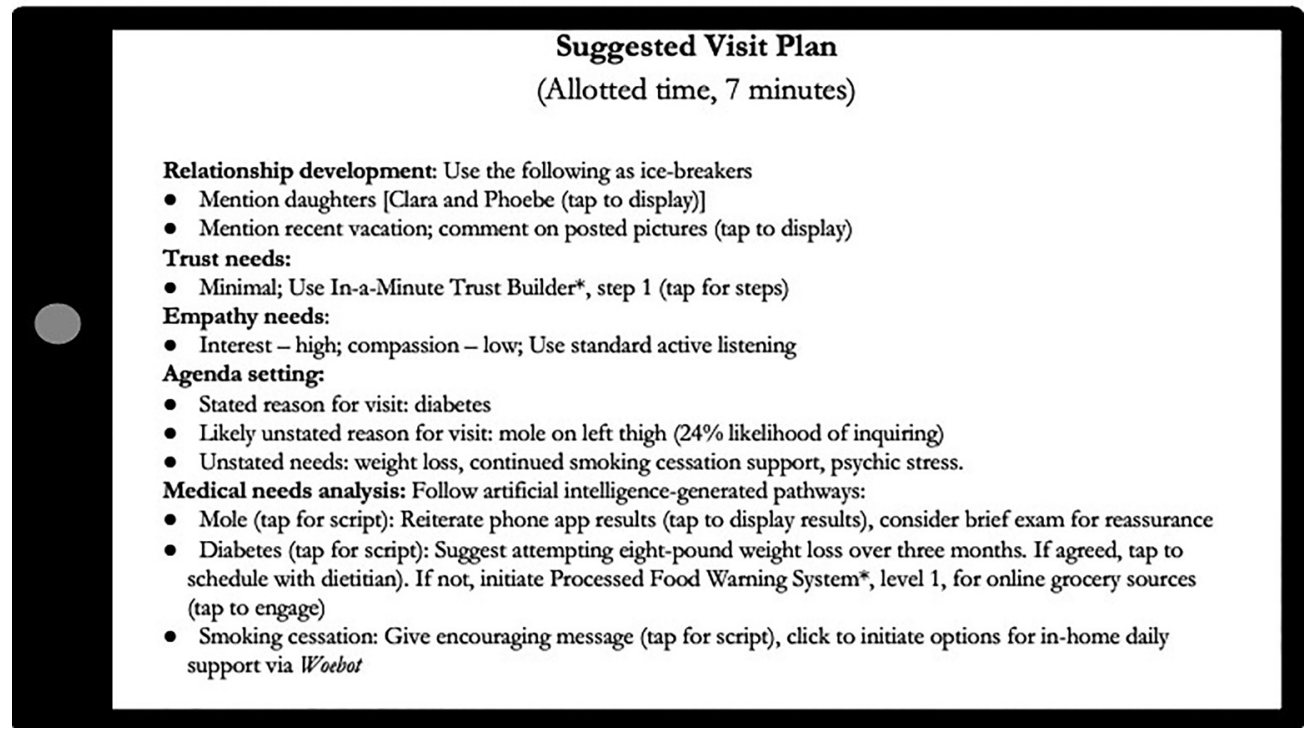

between patient and doctor and to between customers and accountable care organizations ${ }^{19}$ think about the "relationships" people have with organizations such as Walmart, Apple, or their preferred news source.

How will the addition of technology change patients' perceptions of their care? The introduction of the computer into the examination room increased patients' satisfaction with their visits and improved perceptions of their physicians' familiarity with them, without interfering with communication about psychosocial issues. ${ }^{20}$ Patients may at first be surprised by the level of data that can be collected about them, but as the Internet has evolved, so too has the tolerance of most people for having their data tracked.

What does that mean for technologies to be introduced so rapidly into a complex system? Who bears the costs, who controls and owns of all this information, who aggregates the data, and who is responsible for data quality and validity? Medicine has been plagued with a penchant for embracing new technologies that turn out to be ineffective or harmful. $^{21}$ The failures of IBM Watson to select appropriate treatment for cancer ${ }^{22}$ and the Apple Watch $^{23}$ to monitor for atrial fibrillation are 2 recent examples. Most of these technologies are being developed by organizations outside of medicine that lack a fundamental understanding of the process of care and may be introduced more rapidly than our ability to evaluate them.
Simply layering all this new information on top of this connection, though, will not work, for we risk becoming slaves to technology. ${ }^{24}$ Too much information breeds uncertainty and anxiety. The best intentions, if coupled with incomplete or misleading information, can lead to overdiagnosis and overtreatment, the unintended harm from too much medicine. ${ }^{25,26}$ What is needed is wisdom, the appropriate application of knowledge to a particular situation based on intuition gained from experience. ${ }^{27}$ Making decisions better means discerning between the right amount of care and too much. The best care emerges out of a shared understanding between physician and patient, the product of the human connection and the ability to manage complexity using the best evidence. The ability to do both gives a family medicine physician the skills to leverage but also control the coming big data.

Many are confident that technology and better management of data will result in higher-quality care and a lower cost. The ability to collect, aggregate, and analyze data can save time, improve record keeping, and help, but not replace, clinical decision-making. It may help us see patients better and to have patients be seen. Like the stethoscope, the new technologies may be foreign and opposed to all our habits and associations. But like the smartphone, they may soon be indispensable. Artificial intelligence, though, has not answered the question posed by Eliot, "Where is the wisdom we 
have lost in knowledge? Where is the knowledge we have lost in information?"

To see this article online, please go to: bttp://jabfm.org/content/ 34/2/430.full.

\section{References}

1. Laennec RTH, Forbes J. A treatise on the diseases of the chest and on mediate auscultation. From the 4th London ed. Philadelphia: Desilver, Thomas; 1835.

2. Athenahealth's take on HIMSS20 trends: primary care disruption, AI and competitive data access. 2020. Available from: https://www.healthcareitnews.com/ news/athenahealth-s-take-himss20-trends-primarycare-disruption-ai-and-competitive-data-access. Accessed April 20, 2020.

3. The disruption of primary care: how customerobsessed companies are changing everything. 2020. Available from: https:/www.chartis.com/forum/wpcontent/uploads/2018/06/WP_The-Disruption-ofPrimary-Care_Final.pdf. Accessed April 20, 2020.

4. Collins JC. Good to great: why some companies make the leap-and others don't. New York, NY: HarperBusiness; 2001.

5. Amazon Care: healthcare built around you. 2020. Available from: https://amazon.care/. Accessed July 14, 2020.

6. Piernas C, Aveyard P, Lee C, et al. Evaluation of an intervention to provide brief support and personalized feedback on food shopping to reduce saturated fat intake (PC-SHOP): A randomized controlled trial. PLoS Med 2020;17:e1003385.

7. Insel TR. Digital phenotyping: technology for a new science of behavior. JAMA 2017;318:1215-6.

8. Mindstrong. 2020. Available from: https://mindstrong. com/science/.

9. Autism \& Beyond. 2020. Available from: https:// autismandbeyond.researchkit.duke.edu/study.

10. Vocalis Health. 2020. Available from: https:// vocalishealth.com/.

11. CallMiner. What is sentiment analysis. 2020. Available from: https://callminer.com/advantages/ sentiment-analysis/. Accessed July 14, 2020.

12. Zuboff S. The age of surveillance capitalism: the fight for a human future at the new frontier of power. New York (NY): Public Affairs; 2019, p. 602.

13. Google Health. Overview. 2020. Available from: https://health.google/. Accessed April 17, 2020.

14. Apple. Health care. 2020. 2020. Available from: https://www.apple.com/healthcare/. Accessed April $17,2020$.
15. Hoff T. Next in line: lowered care expectations in the age of retail- and value-based health. Oxford (UK): Oxford University Press; 2018.

16. Meza JP, Passerman DS. Integrating narrative medicine and evidence-based medicine: the everyday social practice of healing. New York (NY): Radcliffe; 2011.

17. Brody H. "My story is broken; can you help me fix it?" Medical ethics and the joint construction of narrative. Lit Med 1994;13:79-92.

18. Duggan AP. Health and illness in close relationships. New York (NY): Cambridge University Press; 2018.

19. Kemp E, Jillapalli R, Enrique B. Healthcare branding: developing emotionally based consumer brand relationships. J Services Marketing 2014;28: 126-37.

20. Hsu J, Huang J, Fung V, Robertson N, Jimison H, Frankel R. Health information technology and physician-patient interactions: impact of computers on communication during outpatient primary care visits. J Am Med Inform Assoc 2005;12:474-80.

21. Grimes DA. Technology follies: the uncritical acceptance of medical innovation. JAMA 1993;269:3030-3.

22. IBM's Watson supercomputer recommended "unsafe and incorrect" cancer treatments, internal documents show. 2018. Available from: https://www.statnews. com/2018/07/25/ibm-watson-recommended-unsafeincorrect-treatments/. Accessed July 1, 2020.

23. Perez MV, Mahaffey KW, Hedlin H, Apple Heart Study Investigators, et al. Large-scale assessment of a smartwatch to identify atrial fibrillation. $\mathrm{N}$ Engl J Med 2019;381:1909-17.

24. Ebell MH. Foreword. In: Meza JP, Passerman DS, eds. Integrating narrative medicine and evidencebased medicine: the everyday social practice of healing. London: Radcliffe; 2011.

25. Slawson D, Shaughnessy AF. Reducing overuse by recognising the unintended harms of good intentions. BMJ Evid Based Med 2019. Available from: https://ebm.bmj.com/content/early/2019/08/23/ bmjebm-2019-111247.

26. Gervas J, Oliver LL, Perez-Fernandez M. Family and community medicine and its role in preventing health overuse (preventive, diagnostic, therapeutic and rehabilitative). Cien Saude Colet 2020;25:1233-40.

27. Slawson DC, Shaughnessy AF, Bennett JH. Becoming a medical information master: feeling good about not knowing everything. J Fam Pract 1994;38:505-13.

28. Mole Monitor. 2020. Available from: http://www. mole-monitor.com/. Accessed July 14, 2020. 